\title{
Unexpected renal hemorrhage after endovascular repair of complicated type B aortic dissection: two cases report
}

Hongwei Zhang ${ }^{1 \dagger}$, Bangsheng Jia ${ }^{2 \dagger}$, Ling Zeng ${ }^{3 \dagger}$, Zhenghua Xiao ${ }^{1}$, Jiayu Shen ${ }^{1}$, Hong Qian ${ }^{1}$, Eryong Zhang ${ }^{1}$ and Jia Hu${ }^{1 *}$

\begin{abstract}
Background: Thoracic endovascular aortic repair (TEVAR) is the therapeutic choice for type B aortic dissection. One of the most unfavored complications of this procedure is hemorrhage, which has a low incidence but high mortality. Renal hemorrhage $(\mathrm{RH})$ after endovascular aortic repair has been rarely reported. We presented two cases of unexpected RH after TEVAR for complicated type B aortic dissection, and the potential causes, diagnosis and therapeutic management were discussed.

Case presentation: A 67-year-old female developed hypotension and progressively decrease of hemoglobin within $5 \mathrm{~h}$ after TEVAR for acute complicated type B dissection. Bedside ultrasonography and abdominal computed tomography angiography revealed a massive right perinephric hematoma. The right renal angiography detected multiple tortuous vascular branches with diffuse perinephric bleeding. The main trunk of right renal artery was embolized. The patient recovered uneventfully and presented with normal renal function 6 months later. Another patient was a 69-year-old male who was admitted for endovascular repair of a chronic complicated type B aortic dissection. The patient presented with hemodynamic instability early after TEVAR. Bedside ultrasonography showed a giant left retroperitoneal hematoma. The abdominal angiography revealed two active bleeding sits located in the distal branches of left renal artery. A super-selective embolization of the two arteries was performed, however the patient developed abdominal compartment syndrome and died of multiple organ failure.

Conclusions: Unexpected $\mathrm{RH}$ after endovascular repair of aortic dissection might be associated with iatrogenic and idiopathic factors. Close surveillance and clinician's awareness of this rare complication is crucial for accurate and prompt diagnosis. Renal angiography and subsequent selective embolization of bleeding vessels are effective interventions for treating this fatal condition.
\end{abstract}

Keywords: Renal hemorrhage, Thoracic endovascular aortic repair, Complicated type B aortic dissection

\section{Background}

Thoracic endovascular aortic repair (TEVAR) is the therapeutic choice for type B aortic dissection [1-3]. One of the most unfavored complications of this procedure is hemorrhage, which has a low incidence but high mortality [1-3]. To our best knowledge, renal hemorrhage (RH)

\footnotetext{
* Correspondence: humanjia@msn.com

${ }^{\dagger}$ Hongwei Zhang, Bangsheng Jia and Ling Zeng contributed equally to this work.

${ }^{1}$ Department of Cardiovascular Surgery, West China Hospital, Sichuan University, Chengdu, Sichuan, People's Republic of China

Full list of author information is available at the end of the article
}

after endovascular aortic repair has been rarely reported. In the present study, we presented two cases of unexpected RH after TEVAR for complicated type B aortic dissection, and the potential causes, diagnosis and therapeutic management were discussed.

\section{Case presentation}

\section{Case 1}

A 67-year-old female patient presented in the emergency department with persistent chest pain for $12 \mathrm{~h}$, followed by aggravating lower limbs numbness and oliguria, with a urine output of $40 \mathrm{ml}$ after onset. Computed tomography

(c) The Author(s). 2018 Open Access This article is distributed under the terms of the Creative Commons Attribution 4.0 International License (http://creativecommons.org/licenses/by/4.0/), which permits unrestricted use, distribution, and 
angiography (CTA) revealed an acute type B aortic dissection with a primary entry tear approximating to the left subclavian artery (LSA) and extending to the iliac arteries (Fig. 1a). Left renal artery originated from a severely stenotic true lumen, right renal artery with dynamic occlusion was supplied via a false lumen (Fig. 1b), and there were two cysts $(28 \mathrm{~mm} \times 25 \mathrm{~mm}, 10 \mathrm{~mm} \times 10 \mathrm{~mm})$ separately located at the upper and inferior poles of right kidney (Fig. 1c). Incomplete thrombosis was detected in the bilateral common iliac arteries (Fig. 1d).

The patient underwent emergent TEVAR $3 \mathrm{~h}$ after admission because of the malperfusion symptoms of right kidney and lower extremity. A hydrophilic angled guidewire $(0.035$ in. $\times 180 \mathrm{~cm}$; Radifocus, Terumo) was inserted into the aortic true lumen via the right femoral artery, and the angiography showed poor perfusion of the right kidney and bilateral iliac arteries (Fig. 1e). The distal restrictive covered stent (straight $24 \mathrm{~mm} \times 80 \mathrm{~mm}$; Endurant, Medtronic) was introduced and deployed at the proximal descending aorta. Subsequently, the thoracic stent graft (straight $36 \mathrm{~mm} \times$ $200 \mathrm{~mm}$; Valiant Captiva, Medtronic) was introduced, overlapped $30 \mathrm{~mm}$ with the restrictive stent and deployed at the distal aortic arch (Additional file 1). The LSA was sacrificed because of inadequate proximal landing zone and the dominant right vertebral artery. Completion angiography demonstrated a satisfactory coverage of the primary entry tear, and the reopening of the distal true lumen and an improved flow in right renal artery and bilateral iliac arteries (Fig. 1f).

Although the distal malperfusion syndrome was successfully treated, the patient showed hemodynamic instability and progressively decrease of hemoglobin from 118 to $82 \mathrm{~g} / \mathrm{L}$ within $5 \mathrm{~h}$ after surgery. Bedside ultrasonography and abdominal CTA revealed a massive right perinephric hematoma measuring $10 \mathrm{~cm} \times 15 \mathrm{~cm}$ (Fig. 2a, b). As her vital signs were unstable even after 6 units of blood transfusion and another $2000 \mathrm{ml}$ of fluid resuscitation within $4 \mathrm{~h}$, an emergency transcatheter embolization was performed. The right renal angiography detected multiple tortuous vascular branches with diffuse perinephric bleeding (Fig. 2c). The main trunk of right renal artery was embolized with metallic microcoils (0.035 in.; Cook) and histoacryl glue (B. Braun) (Fig. 2d, Additional file 1).

The patient was hemodynamically stable, and the hemoglobin returned to normal. Although a period of renal insufficiency with the maximum serum creatinine level reaching $343 \mu \mathrm{mol} / \mathrm{L}$ was observed after surgery, the patient maintained normal urine output (1200-1500 $\mathrm{ml} /$ day) without any hemodialysis. The patient recovered uneventfully, and no signs of hemorrhage of the right kidney were detected by pre-discharge CTA 7 days after TEVAR (Fig. 2e, f). Six-month follow-up showed the patient was in good condition and presented with normal renal function.
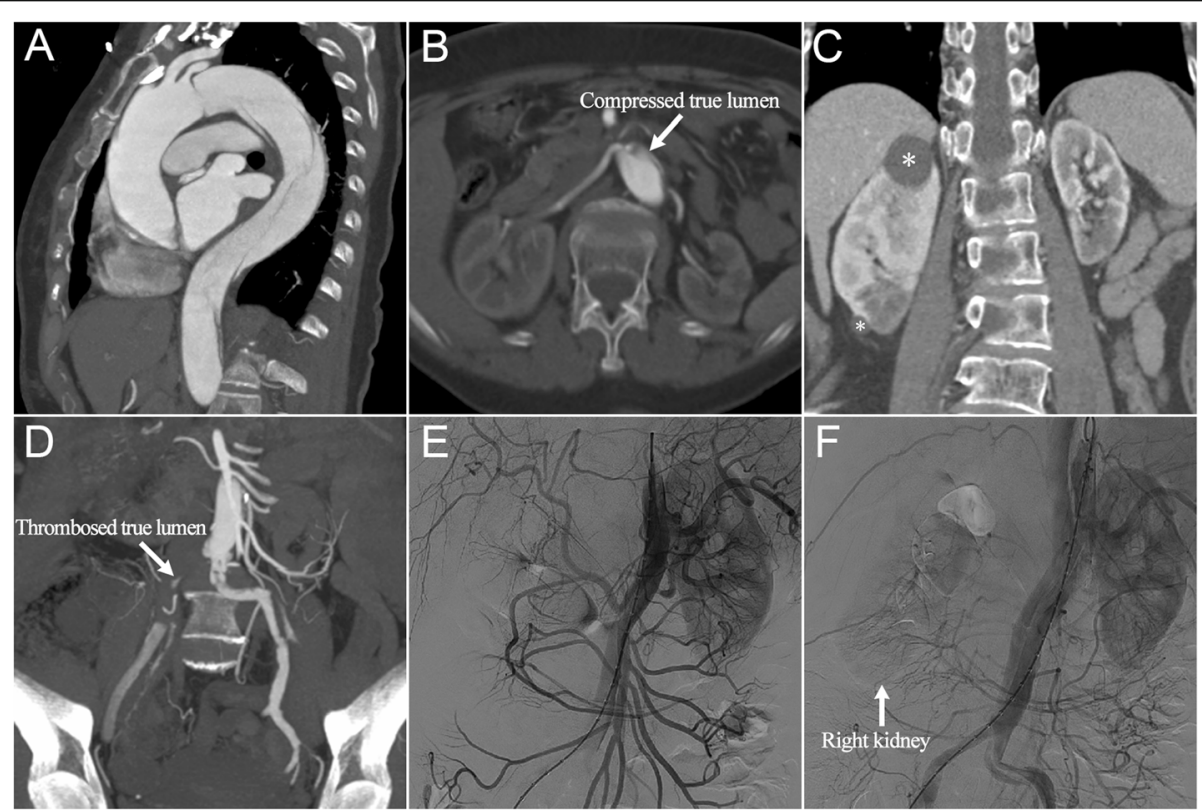

Fig. 1 (a) Preoperative sagittal computed tomography angiography showed type B aortic dissection. (b) Left renal artery originated from a severely stenotic true lumen, right renal artery with dynamic occlusion was supplied via a false lumen. (c) Two cysts (asterisks) were separately located at the upper and inferior poles of right kidney. (d) Incomplete thrombosis was detected in the bilateral common iliac arteries. (e) Abdominal angiography showed poor perfusion of the right kidney and bilateral iliac arteries, and (f) completion angiography demonstrated the reopening of the distal true lumen and an improved flow in right renal artery and bilateral iliac arteries 

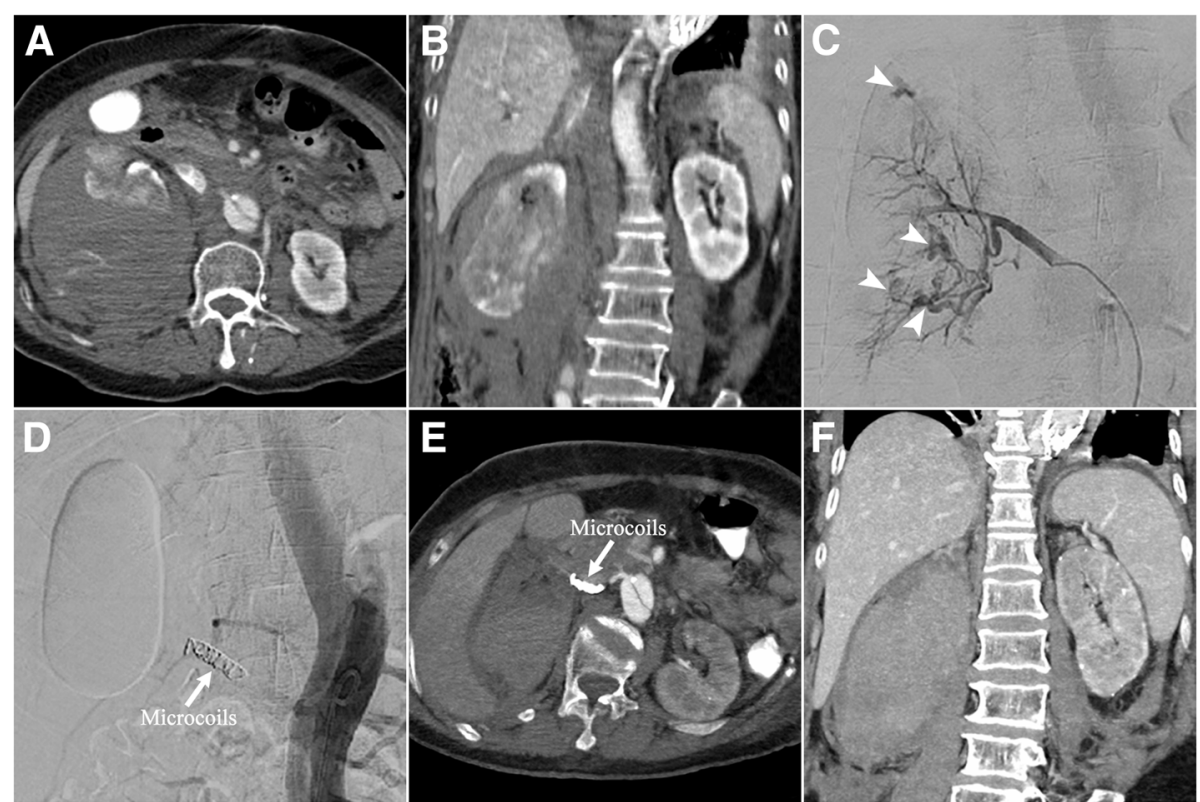

Fig. 2 (a) Transverse and (b) coronal computed tomography angiography showed a massive right perinephric hematoma. (c) Right renal angiography detected multiple tortuous vascular branches with diffuse perinephric bleeding (arrowheads), and (d) the main trunk of right renal artery was embolized with microcoils. (e, f) Pre-discharge computed tomography angiography showed no signs of hemorrhage of the right kidney

\section{Case 2}

Another patient was a 69-year-old male who was admitted for endovascular repair of a chronic complicated type B aortic dissection. He had history of poorly controlled hypertension for 10 years due to irregular intake of antihypertensive medications. The dissection ranged from the distal aortic arch to the iliac arteries (Fig. 3a). The left renal artery originated from the true lumen, and the right renal artery was supplied via both the true and false lumen, no cysts or tumors were found in both kidneys (Fig. 3b, c).

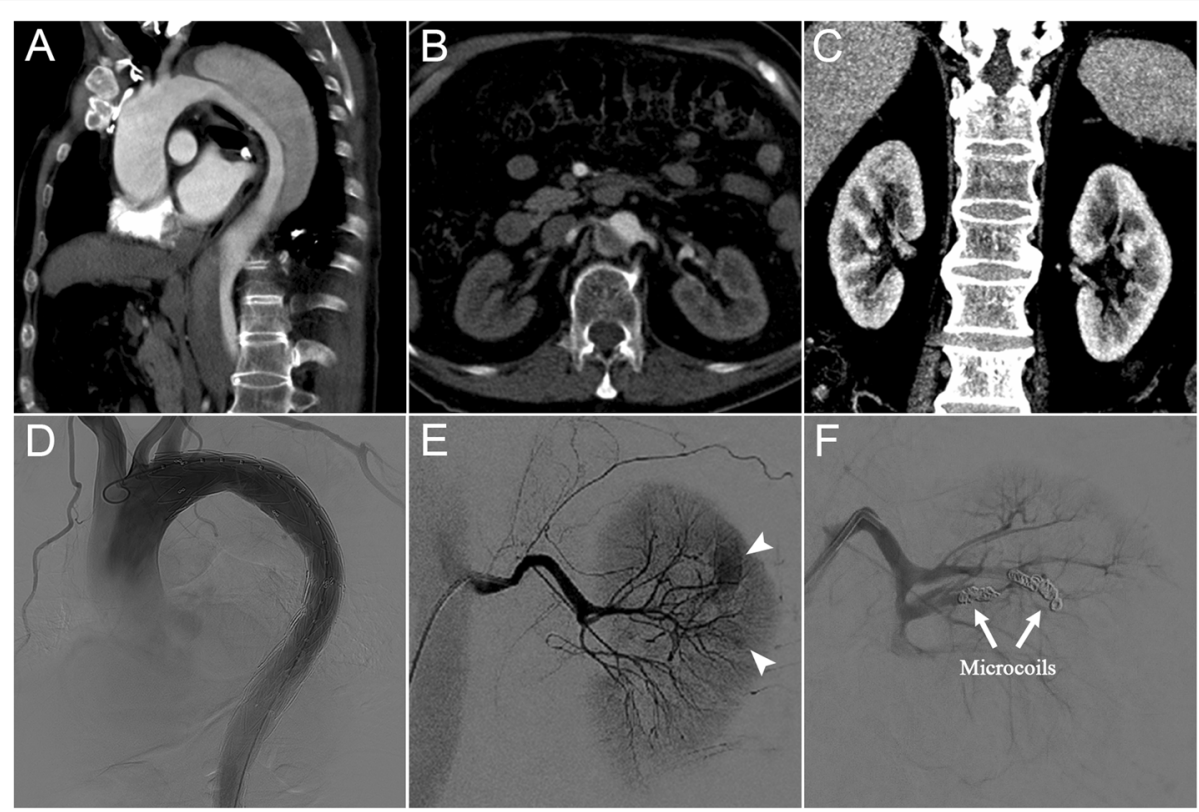

Fig. 3 (a) Preoperative sagittal computed tomography angiography showed a type B dissection ranging from the distal aortic arch to the iliac arteries. (b) The left renal artery originated from the true lumen, and (c) without cysts or tumors. (d) Completion angiography showed the entry tear was successfully occluded. (e) Left renal angiography revealed two active bleeding sits located in the distal branches of left renal artery (arrowheads). (f) Completion angiography showed the effective occlusion of the feeding vessel and termination of the left renal bleeding 
TEVAR was accepted as a reasonable treatment strategy after the consent of the patient. Through right femoral artery, the first (distal) (tapered $28 \mathrm{~mm}-24 \mathrm{~mm} \times$ $150 \mathrm{~mm}$; Valiant Captiva, Medtronic) and the second (proximal) (straight $34 \mathrm{~mm} \times 200 \mathrm{~mm}$; Valiant Captiva, Medtronic) thoracic stent grafts were accurately deployed without sacrificing LSA, and the entry tear was successfully occluded (Fig. 3d, Additional file 2).

The patient complained of left flank pain and presented with hemodynamic instability early after TEVAR. His systolic blood pressure rapidly decreased to less than $80 \mathrm{mmHg}$, and the hemoglobin value sharply dropt from 122 to $64 \mathrm{~g} / \mathrm{L}$ within only $2 \mathrm{~h}$ postoperatively, even intravenous bolus administration and massive blood transfusion could not maintain his vital signs stable. Bedside ultrasonography showed a giant left retroperitoneal hematoma. Progressively hemodynamic instability forced cessation of further radiological examination. The patient was immediately transferred to the operating room for emergency transcatheter embolization because of highly suspicious of left $\mathrm{RH}$. The abdominal angiography revealed two active bleeding sits located in the distal branches of left renal artery, and no bleeding sites were found at the aorta and other branches (Fig. 3e, Additional file 2). A super-selective embolization of two renal arterial branches was performed with metallic microcoils (0.018 in.; Cook) and histoacryl glue (B. Braun). Completion angiography showed effective occlusion of the feeding vessel and termination of the left renal bleeding (Fig. 3f, Additional file 2). The patient developed abdominal compartment syndrome and died of multiple organ failure 2 days after surgery.

\section{Discussion}

Endovascular repair has been increasingly used for treating aortic diseases [1-3]. A series of complications after TEVAR are associated with vascular injury, resulting in branch vessel rupture and active bleeding [1-3]. Active $\mathrm{RH}$ is a rare but life-threatening complication after endovascular procedures. Identification of its potential etiology is important to prevent the occurrence of this catastrophic event.

Unexpected hemorrhage of visceral organs after endovascular aortic repair is usually caused by iatrogenic injuries of the branch vessels during wires, catheters or sheaths insertion. [4-8]. It was reported that the incidence of iatrogenic injuries after percutaneous renal artery revascularization had been $6.5-22.8 \%[4,7,8]$. As reported by several studies $[4,5,7,8]$, the iatrogenic perforation and rupture of small branch vessels are usually caused by floppy-tipped guidewires. The hydrophilic guidewires and catheters may accidently enter the renal arterial branches during wire exchanging procedures, when it was performed without any fluoroscopic navigation $[4,5,7$,
8]. Particularly in patients with aortic dissection, the true lumen is usually compressed by enlarged false lumen [3], and the guidewire may easily pass through the narrowed true lumen into the downward angled renal artery. In the present study, the most likely cause of $\mathrm{RH}$ in the second patient was guidewire-induced injuries of small branches of renal arteries. Therefore, careful manipulation of guidewires under full fluoroscopic navigation is crucial to avoid unexpected branch vessel injury during endovascular procedures.

Although iatrogenic artery injury was reported as the leading cause of $\mathrm{RH}$, the first patient in this study showed an uncommon cause of post-TEVAR hemorrhage of kidneys. Existing evidence has demonstrated that reperfusion syndrome contributes to idiopathic bleeding following endovascular artery revascularization [9-12]. The typical $\mathrm{RH}$ caused by reperfusion injury occurs after stenotic renal artery stenting $[9,10]$. Despite the difference between TEVAR and renal revascularization, but they share the similar pathogenesis in causing reperfusion hemorrhage. However, RH attributed to reperfusion injury after successful endovascular repair of aortic dissection was not reported previously. In aortic dissection patients with renal ischemia or abnormalities, such as tumors, cysts or aneurysms, the capsular branches are extremely fragile [3, 13]. RH may occur when these branches are suddenly subjected to the remarkable increased pressure after reopening of the distal true lumen. Owing to the multifocal bleeding of right kidney, the idiopathic hemorrhage of the first patient who presented with renal malperfusion might be ascribed to ischemia-reperfusion injury. Nevertheless, the cause of renal bleeding located at the upper pole could not exclude cyst rupture. Consequently, for the patients with complicated type $\mathrm{B}$ dissection, especially for those accompanied with renal malperfusion or abnormalities, more attention should be paid to the possibility of unexpected $\mathrm{RH}$ after TEVAR.

The survival of the patient often depends on early and accurate diagnosis, since $\mathrm{RH}$ is an insidious and lethal complication of TEVAR. The patients are recommended to be routinely sent to the observation room for careful surveillance at early postoperative period. $\mathrm{RH}$ should be alerted if the patient presents with progressively decrease of hemoglobin, hypotension, tachycardia and acute ipsilateral abdominal/flank pain $[6,14,15]$. Rapid diagnosis of RH relies on proper imaging. CTA has been regarded as an excellent diagnostic modality for hemorrhage with high sensitivity [15-18]. Charbit et.al reported that small renal hematoma less than $25 \mathrm{~mm}$ without active extravasation of contrast on CTA could exclude an indication for embolization [17]. Since CTA investigation is time consuming, it could delay an early effective treatment for patients with active bleeding. CTA was not used in the second patient who had already presented with 
hemodynamic instability, and bedside ultrasonography was performed for both patients. Ultrasonography can be fast and convenient to detect renal subcapsular fluid collection or perirenal hematoma $[18,19]$, thus it is useful for rapid identification of $\mathrm{RH}$, especially for patients who require expeditious intervention. Catheter angiography remains the golden standard for the diagnosis of $\mathrm{RH}$, and it can clearly locate the bleeding sites and provide the chance for possible embolization simultaneously $[14,15]$. We suggest that a diagnostic angiography being timely undertaken for all patients with suspected RH after TEVAR, especially for those with active hemorrhage in case of treatment delay.

An optimal decision-making relies on a comprehensive clinical assessment. Most renal vascular injuries are spontaneous cured, and conservative treatment is recommended to patients who are hemodynamic stable with no evidence of ongoing hemorrhage [6, 8, 15-17]. Urgent intervention is indicated for patients with massive bleeding, uncontrolled hemorrhage lasting for more than $72 \mathrm{~h}$, or progressively deterioration of the renal function [20]. Compared with open surgery, transcatheter embolization has been established as a preferred treatment for RH after TEVAR [6, 14-17, 20-22]. Superselective renal embolization is a minimally invasive and effective procedure for $\mathrm{RH}$, and definitely minimizes the damage of normal renal parenchyma, thus maintaining renal functional and preventing post-embolization syndrome [14-16, 20, 22]. Emergent embolization of renal arteries was a life-saving treatment of choice for our cases.

\section{Conclusion}

Unexpected RH after endovascular repair of aortic dissection might be associated with iatrogenic and idiopathic factors. Close surveillance and clinician's awareness of this rare complication is crucial for accurate and prompt diagnosis. Renal angiography and subsequent selective embolization of bleeding vessels are effective interventions for treating this fatal condition.

\section{Additional files}

Additional file 1: The procedures of thoracic endovascular aortic repair and right renal embolization for the first patient. (MP4 23804 kb)

Additional file 2: The procedures of thoracic endovascular aortic repair and left renal embolization for the second patient. (MP4 11521 kb)

\section{Abbreviations}

CTA: Computed tomography angiography; LSA: left subclavian artery; $\mathrm{RH}$ : Renal hemorrhage; TEVAR: Thoracic endovascular aortic repair

\section{Acknowledgments}

Not applicable.

\section{Funding}

This study was supported in part by the National Natural Science Foundation of China (No.81300155 and 81670327).
Availability of data and materials

All data generated or analyzed during this study are included in this published article.

\section{Authors' contributions}

HWZ, BSJ, LZ and JH involved in study design, patients management, data analysis and manuscript drafting. ZHX, JYS and HQ participated in the surgeries of two patients and collected the data. EYZ revised the manuscript. All authors read and approved the final manuscript.

\section{Ethics approval and consent to participate}

Not applicable.

\section{Consent for publication}

Written informed consent for publication of the case reports and any accompanying images was obtained from the patients or their families.

\section{Competing interests}

The authors declare that they have no competing interests.

\section{Publisher's Note}

Springer Nature remains neutral with regard to jurisdictional claims in published maps and institutional affiliations.

\section{Author details}

${ }^{1}$ Department of Cardiovascular Surgery, West China Hospital, Sichuan University, Chengdu, Sichuan, People's Republic of China. ${ }^{2}$ Department of Radiology, West China Hospital, Sichuan University, Chengdu, Sichuan, People's Republic of China. ${ }^{3}$ Department of Intensive Care Unit, West China Hospital, Sichuan University, Chengdu, Sichuan, People's Republic of China.

Received: 14 November 2017 Accepted: 7 November 2018

Published online: 16 November 2018

\section{References}

1. Erbel R, Aboyans V, Boileau C, Bossone E, Bartolomeo RD, Eggebrecht $H$, et al. 2014 ESC guidelines on the diagnosis and treatment of aortic diseases: document covering acute and chronic aortic diseases of the thoracic and abdominal aorta of the adult. The task force for the diagnosis and treatment of aortic diseases of the European Society of Cardiology (ESC). Eur Heart J. 2014;35(41):2873-926.

2. Grabenwöger M, Alfonso F, Bachet J, Bonser R, Czerny M, Eggebrecht $H$, et al. Thoracic endovascular aortic repair (TEVAR) for the treatment of aortic diseases: a position statement from the European Association for CardioThoracic Surgery (EACTS) and the European Society of Cardiology (ESC), in collaboration with the European Association of Percutaneous Cardiovascular Interventions (EAPCI). Eur Heart J. 2012;33(13):1558-63.

3. Nienaber CA, Clough RE, Sakalihasan N, Suzuki T, Gibbs R, Mussa F, et al. Aortic dissection. Nat Rev Dis Primers. 2016;2:16053.

4. Yi JS, Lee HJ, Lee HJ, Yang JH. Renal subcapsular hematoma after percutaneous transfemoral angiography. J Korean Neurosurg Soc. 2014;55(2):96-8.

5. Lee SY, Kim SM, Bae JW, Hwang KK, Bae IH, Kim DW, et al. Renal artery perforation related with hydrophilic guide wire during coronary intervention: successful treatment with polyvinyl alcohol injection. Can J Cardiol. 2012;28(5):612.e5-7.

6. Chan YC, Morales JP, Reidy JF, Taylor PR. Management of spontaneous and iatrogenic retroperitoneal haemorrhage: conservative management, endovascular intervention or open surgery? Int J Clin Pract. 2008;62(10): 1604-13.

7. Fang CC, Ng Jao YT, Han SC, Wang SP. Renal subcapsular hematoma after cardiac catheterization. Int J Cardiol. 2007;117(3):e101-3.

8. Morris CS, Bonnevie GJ, Najarian KE. Nonsurgical treatment of acute iatrogenic renal artery injuries occurring after renal artery angioplasty and stenting. AJR Am J Roentgenol. 2001;177(6):1353-7.

9. Kang KP, Lee S, Kim W, Han YM, Kang SK, Park SK. Renal subcapsular hematoma: a consequence of reperfusion injury of long standing renal artery stenosis. Electrolyte Blood Press. 2007;5(2):136-9.

10. Aytekin C, Yildirim UM, Ozyer U, Harman A, Boyvat F. Emergency renal ablation for life-threatening hemorrhage from multiple capsular branches during renal artery stenting. Cardiovasc Intervent Radiol. 2010;33(3):663-6. 
11. Abou-Chebl A, Yadav JS, Reginelli JP, Bajzer C, Bhatt D, Krieger DW. Intracranial hemorrhage and hyperperfusion syndrome following carotid artery stenting: risk factors, prevention, and treatment. J Am Coll Cardiol. 2004:43(9):1596-601.

12. Moore M, McSweeney S, Fulton G, Buckley J, Maher M, Guiney M. Reperfusion hemorrhage following superior mesenteric artery stenting. Cardiovasc Intervent Radiol. 2008;31(Suppl 2):S57-61.

13. Ahn T, Roberts MJ, Navaratnam A, Chung E, Wood S. Changing etiology and management patterns for spontaneous renal hemorrhage: a systematic review of contemporary series. Int Urol Nephrol. 2017;49(11):1897-905.

14. Wang $\mathrm{HL}, \mathrm{Xu} \mathrm{CY}$, Wang HH, Xu W. Emergency transcatheter arterial embolization for acute renal hemorrhage. Medicine. 2015;94(42):e1667.

15. Sommer CM, Stampfl U, Bellemann N, Ramsauer S, Loenard BM, Haferkamp A, et al. Patients with life-threatening arterial renal hemorrhage: $C T$ angiography and catheter angiography with subsequent superselective embolization. Cardiovasc Intervent Radiol. 2010;33(3):498-508.

16. Mao Q, Zhong B, Lin Y, Wang C, Liang W, Tan F, et al. Clinical application of computed tomographic angiography in patients with renal arterial hemorrhage: diagnostic accuracy and subsequent therapeutic outcome. Exp Ther Med. 2015;10(2):508-12.

17. Charbit J, Manzanera J, Millet I, Roustan JP, Chardon P, Taourel P, et al. What are the specific computed tomography scan criteria that can predict or exclude the need for renal angioembolization after high-grade renal trauma in a conservative management strategy? J Trauma. 2011;70(5):1219-27.

18. Hammond NA, Lostumbo A, Adam SZ, Remer EM, Nikolaidis P, Yaghmai V, et al. Imaging of adrenal and renal hemorrhage. Abdom Imaging. 2015; 40(7):2747-60

19. Mitreski G, Sutherland T. Radiological diagnosis of perinephric pathology: pictorial essay 2015. Insights Imaging. 2017;8(1):155-69.

20. Mavili E, Dönmez H, Ozcan N, Sipahioğlu M, Demirtaş A. Transarterial embolization for renal arterial bleeding. Diagn Interv Radiol. 2009;15(2):143-7.

21. Pozzi-Mucelli F, Medeot A, Cernic S, Calgaro A, Braini M, Cova M. Multimodal approach to the endovascular treatment of embolisation or exclusion of the renal arteries and their distal and/or polar branches: personal experience. Radiol Med. 2011;116(6):945-59.

22. Wang C, Mao Q, Tan F, Shen B. Superselective renal artery embolization in the treatment of renal hemorrhage. Ir J Med Sci. 2014;183(1):59-63.

Ready to submit your research? Choose BMC and benefit from:

- fast, convenient online submission

- thorough peer review by experienced researchers in your field

- rapid publication on acceptance

- support for research data, including large and complex data types

- gold Open Access which fosters wider collaboration and increased citations

- maximum visibility for your research: over $100 \mathrm{M}$ website views per year

At BMC, research is always in progress.

Learn more biomedcentral.com/submissions 